\title{
A RETROSPECTIVE STUDY ON HISTOID HANSEN'S DISEASE - AN INSIGHT INTO AETIOPATHOGENESIS AND DISEASE PATTERN
}

\author{
Vijayaanand Muthupandian1, Rajkumar Kannan², Balakrishnan Thenmozhi Priya³, Krishnaveni Alagar4 \\ 1 Professor, Department of Dermato-Venereo-Leprology, Kilpauk Medical College, Kilpauk, Chennai. \\ ${ }^{2}$ Assistant Professor, Department of Dermato-Venereo-Leprology, Kilpauk Medical College, Kilpauk, Chennai. \\ ${ }^{3}$ Assitant Professor, Department of Dermato-Venereo-Leprology, Kilpauk Medical College, Kilpauk, Chennai. \\ ${ }^{4}$ Assistant Professor, Department of Dermato-Venereo-Leprology, Kilpauk Medical College, Kilpauk, Chennai.
}

\section{ABSTRACT}

\section{BACKGROUND}

Leprosy has been known to plague the mankind since times immemorial. Leprosy is a chronic granulomatous disease involving skin, peripheral nerves and nasal mucosa but capable of affecting any tissue or organ. According to Madrid, Leprosy is of four types, viz., lepromatous, tuberculoid, dimorphic and indeterminate.

Histoid leprosy is a peculiar, relatively stable, distinct clinical, bacteriological and histopathological expression of multibacillary leprosy ${ }^{1}$ and its exact pathogenesis still remains elusive. Its exact aetiopathogenesis is not well understood, as it may arise de novo or may develop after an inadequate and irregular treatment with Dapsone monotherapy (or) Multidrug Therapy (MDT). ${ }^{2}$

Settings and Design - We are presenting a retrospective case study on Histoid Hansen patients who attended the Leprosy Clinic in a tertiary care centre, between the years 2011 and 2015.

\section{MATERIALS AND METHODS}

A total number of 207 Hansen disease patients who attended the Leprosy Clinic between 2011 and 2015 were included in the study. Out of them, 8 patients were found to be patients of Histoid Hansen. Factors pertaining to duration of the disease, spectrum of Hansen's disease, duration of treatment, mono (or) multi-drug therapy, default if any and reaction patterns among them were studied to gain an insight into aetiopathogenesis and disease pattern.

\section{RESULTS}

Among 8 patients it was found that 5 patients (62\%) had the disease de novo, 2 patients $(25 \%)$ had the disease because of defaulting and in 1 patient (13\%) the disease had occurred in Borderline Lepromatous spectrum.

\section{CONCLUSION}

Histoid Hansen patients pose a great threat to the eradication of leprosy. Early detection and ensuring complete compliance of treatment with Multi-Bacillary Multi-Drug Therapy will help us in achieving the goal of eradication of Leprosy.

\section{KEYWORDS}

Histoid Habitus, Succulent Nodules, Storiform Pattern.

HOW TO CITE THIS ARTICLE: Muthupandian V, Kannan R, Priya BT, et al. A retrospective study on histoid Hansen's disease - an insight into aetiopathogenesis and disease pattern. J. Evolution Med. Dent. Sci. 2016;5(98):7209-7212, D0I: 10. 14260/jemds/2016/1630

\section{BACKGROUND \\ Histoid leprosy is characterised clinically by the presence of numerous skin coloured or erythematous papules and nodules, indurated and infiltrated with no preferred location.(3) Causal factors could be drug resistance to Dapsone, or mutation of strains of Mycobacterium leprae.(4) Treatment with Dapsone alone may create an environment by killing the drug-sensitive micro-organisms, which may allow the growth of resistant bacilli. Apart from occurring in patients on Dapsone monotherapy, it may also occur 'de novo.' Augmented cell-mediated immunity is cardinal and may explain its attempted focalisation of lesions.}

Financial or Other, Competing Interest: None.

Submission 18-11-2016, Peer Review 30-11-2016,

Acceptance 02-12-2016, Published 08-12-2016.

Corresponding Author:

Dr. Vijayaanand Muthupandian,

Department of Dermatology,

Kilpauk Medical College,

Kilpauk, Chennai-600010.

E-mail: cutisvijay@gmail.com

DOI: $10.14260 /$ jemds/2016/1630

\section{(c) (i) $\ominus$}

Histoid leprosy lesions can also be subcutaneous and vary in size from the smallest that can be palpated to the largest of about $5 \mathrm{~cm}$ in diameter. Subcutaneous nodules may also breakdown to form raw-surfaced lesions. Occasionally Histoid leprosy may manifest as plaques. They are sharply delineated plaques, which usually develop at the pressure points. Number of lesions usually varies between 6 and 50. They are usually located over the face, extremities, bony prominence such as knees and elbows. Over the face lesions are most prominent over the middle of forehead, cheeks, tip of the nose and chin. Ear lobes are infrequently affected and loss of eyebrows is unusual. Also lesions of Histoid can involve the unusual sites, viz., lower back, axilla, groin, sub-umbilical area and the penile shaft, the so called "Immune Zone," wherein lesions normally do not occur in the other spectra of Hansen's disease. Mucosal surfaces may be affected and nodules may be encountered on the roof of the mouth (Hard palate) and the glans penis. Nasal mucosa may be affected; however, there is no destruction of the nasal cartilage. Erythema Nodosum Leprosum (ENL) reaction is uncommon.

Slit Skin Smear (SSS) examination of the Histoid Lesion reveals abundance of uniformly staining acid-fast leprosy 
bacilli occurring singly or in parallel clumps. Bacilli are long with tapering ends as compared with ordinary leprosy bacilli. In contrast the surrounding apparently normal skin reveals scant bacilli. Thus, there is a marked discrepancy in the Bacterial Index (BI) from the Histoid Nodule and the surrounding skin.

\section{Histopathology}

Haematoxylin-Eosin stained sections from the Histoid Nodule shows a pseudocapsule surrounding the lesion formed by the compression of the adjacent tissue due to the expanding lesion and conspicuous absence of appendages within the nodule. The presence of numerous thin spindle-shaped histiocytes arranged either in an intertwining, criss-cross or in a storiform or whorled fashion and Fite's staining reveals an abundance of AFB within the spindle-shaped cells.(5) An acellular band (Grenz zone) is located immediately below the epidermis. The AFB is not found in globi formation, as they do not secrete any glial substance. They are longer than normal bacilli, uniform in length and are arranged in parallel bundles along the long axis of histiocytes. Within the histiocytoid collections, there can also be islands of tuberculoid granulomas, which are aptly called by Wade as "contaminating Tuberculoid Bacilli."(6)

Fine Needle Aspiration Cytology of Histoid nodules yields cellular aspirates comprised of cohesive aggregates of spindle shaped macrophages with intracytoplasmic negative images of solid Mycobacterium leprae. Acid fast stain is positive and demonstrates solid uniform staining, long bacilli displaying the characteristic "Histoid Habitus."

We are presenting a retrospective case study of all the Histoid Hansen patients who attended the Leprosy Clinic in a tertiary care centre, between the years 2011 and 2015 .

\section{MATERIALS AND METHODS}

A retrospective study of all the patients of Histoid Hansen, who were diagnosed on the criteria based on clinical findings, fine needle aspiration cytology and histopathology, who attended the Leprosy Clinic at a Tertiary Care Centre between 2011 and 2015 was carried out. Factors pertaining to duration of the disease, spectrum of Hansen's disease, duration of treatment, mono (or) multi-drug therapy, default if any and occurrence of Lepra reaction among them were studied.

\section{RESULTS}

Total number of Leprosy patients registered at the Leprosy Clinic between 2011 and 2015 was 207 amounting to an average of 41 patients per year.

Number of Histoid Hansen patients registered between 2011 and 2015 were 8 patients.

Prevalence rate was 3.86

Among 8 patients of Histoid Hansen 5 were male patients and 3 were female patients, thereby showing male preponderance which correlates well with the results of previous studies.

Among 8 patients of Histoid Hansen, it was found that 5 patients $(62 \%)$ had the disease de novo. Patients had dome shaped, shiny, succulent nodules overlying normal layer of skin (Fig. 1). All patients of de novo disease had lesions in the warm zones (or) immune zones, viz., lower back, axilla and groin.

In 2 patients (25\%), Histoid Hansen had occurred in defaulters.
In 1 patient (13\%), Histoid Hansen had occurred in Borderline-Lepromatous Spectrum downgrading to Lepromatous Leprosy. This particular patient had madarosis of both eyebrows (Fig. 2). Enlarged and thickened greater auricular nerve (Fig. 3), common peroneal and posterior tibial nerves were present. Glove and stocking type of anaesthesia was present. Multiple succulent, juicy nodules and patches over the normal skin (Fig. 4) were seen. Patient also had spontaneous ulceration of certain nodules over the right inframammary area (Fig. 5). Patient also had auto-amputation of right big toe (Fig. 6) and infiltration of both ears (Fig. 7), which is said to be rare in de novo Histoid Hansen. Histopathology of the nodular lesion of all patients under Haematoxylin and Eosin Stain (Fig. 8) revealed nodular collection of plump foamy spindle-shaped histiocytes along with epithelioid cells and plasma cells ("Histoid Habitus").

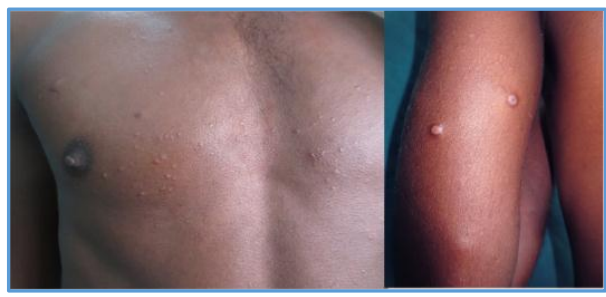

Figure 1. Histoid Hansen - De Novo Case Nodules over Normal Skin

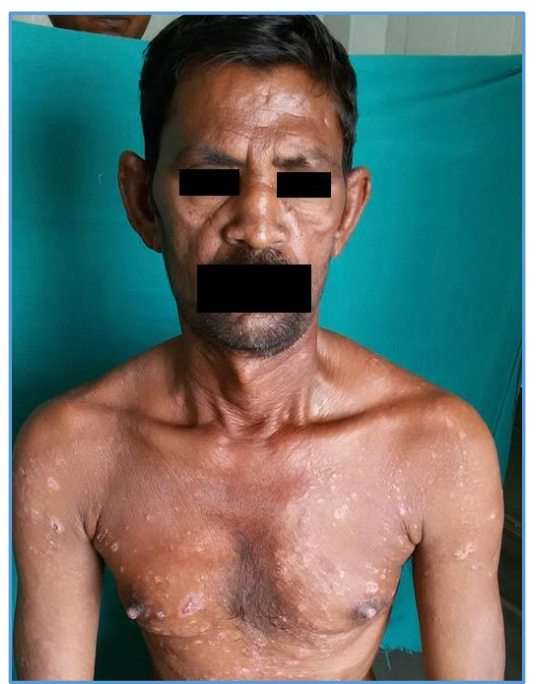

Figure 2. BL-Spectrum shows Madarosis \& Depressed Nasal Bridge

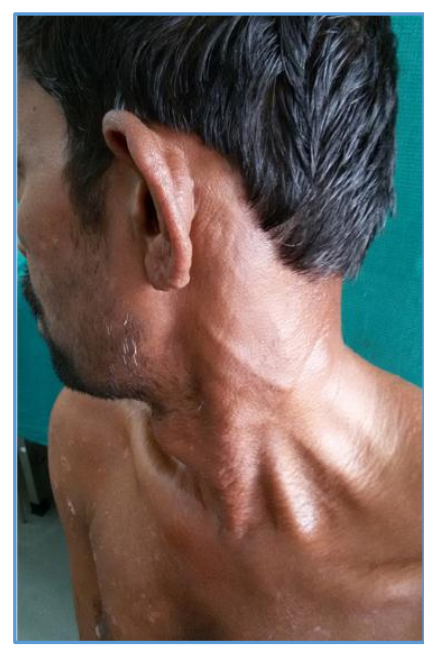

Figure 3. Grossly Thickened Greater Auricular N. Left Side 


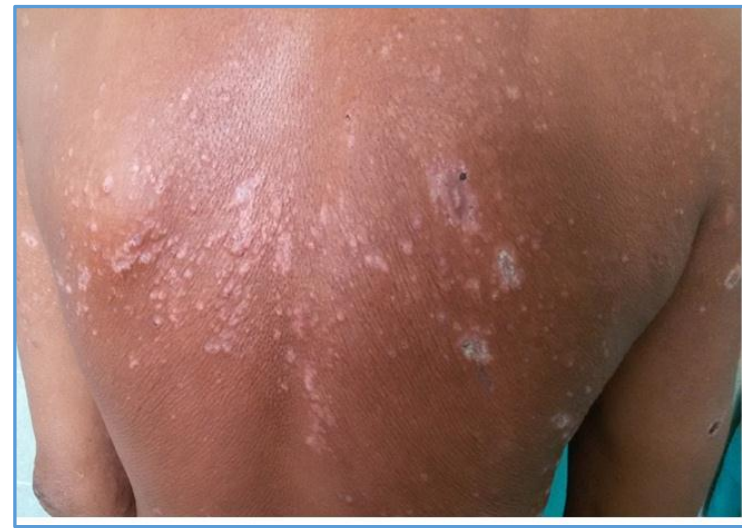

Figure 4. Patches \& Plaques over Back Healing with Psoriasiform Scarring

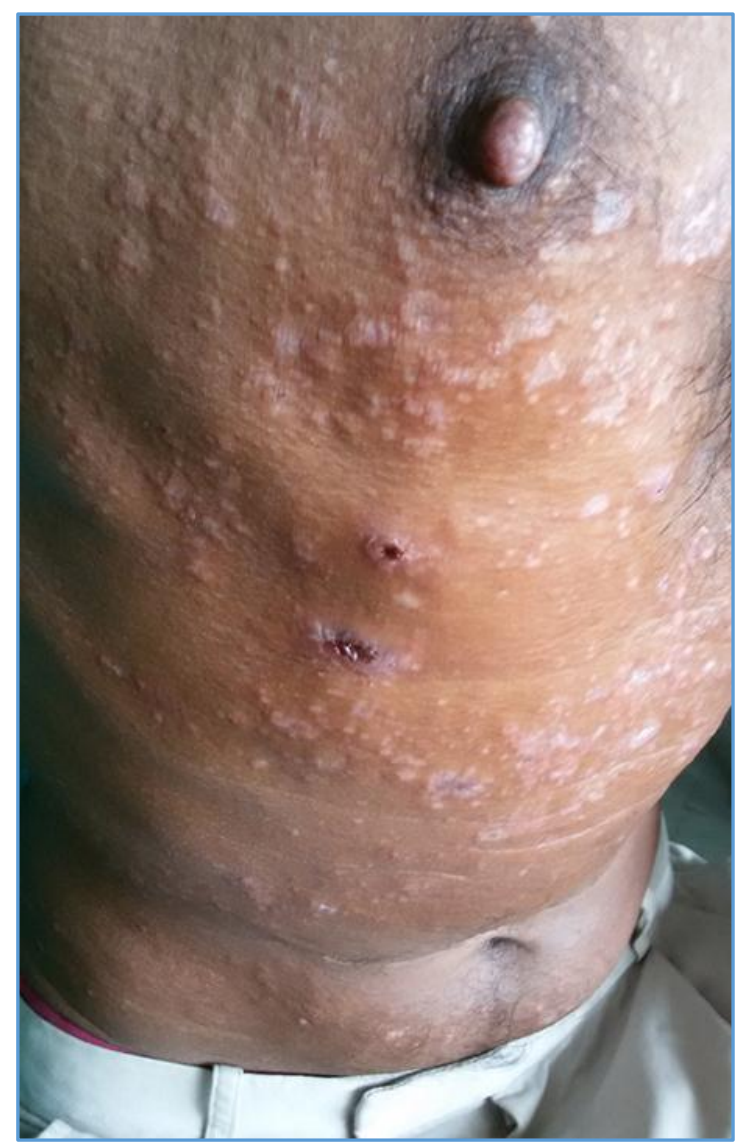

Figure 5. Shows Rt. Gynecothelia \& 2 Ulcerated Rt. Inframammary Nodules Healing

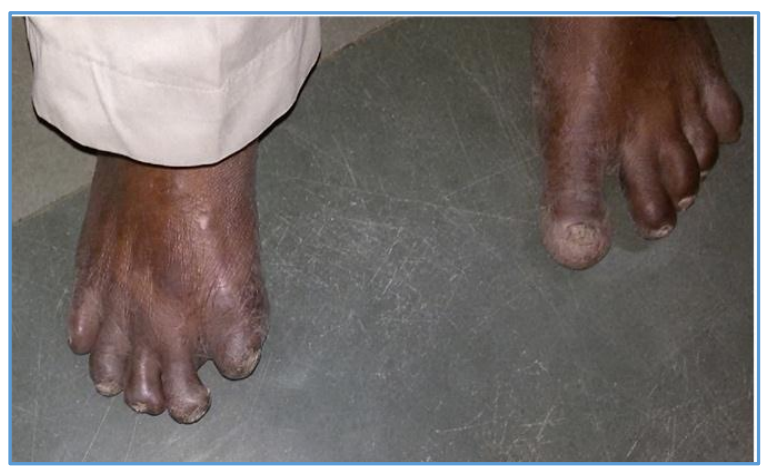

Figure 6. Autoamputation of Rt. Big Toe \& Resorption of Other Toes

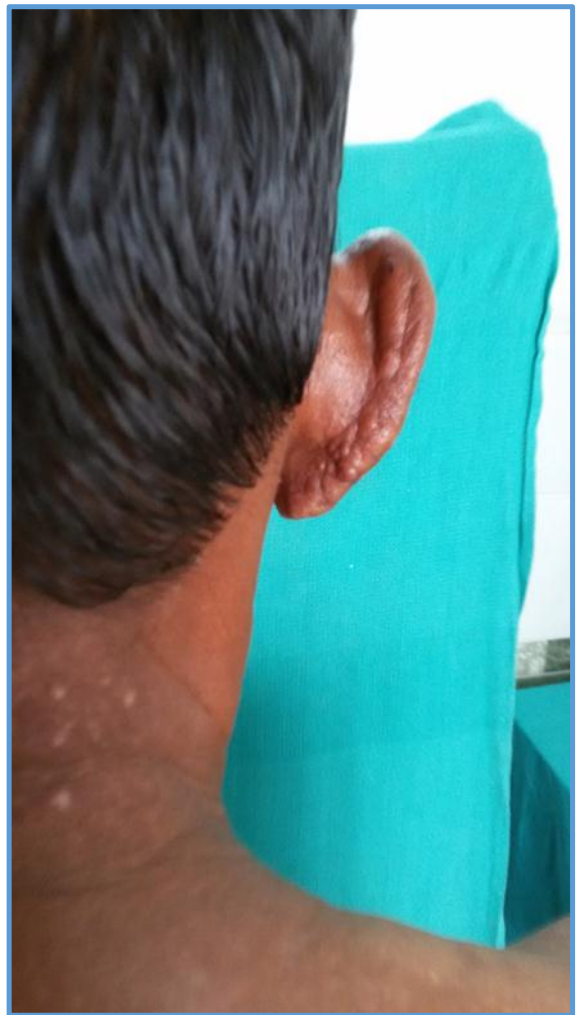

Figure 7. Shows Nodular Infiltrations of Right Ear

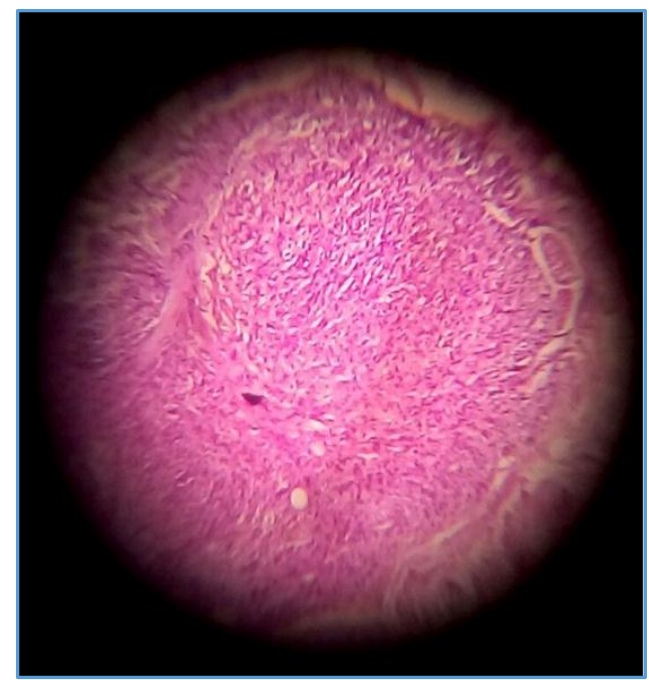

Figure 8. Biopsy-Nodular Lesion-shows Storiform Pattern

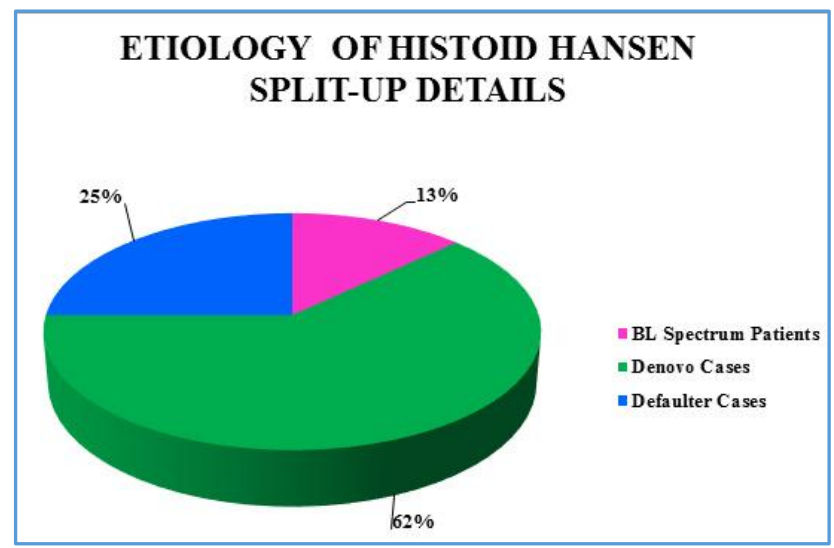




\section{DISCUSSION}

The term Histoid was originally coined in the year 1960 by Wade.(7)

Histoid leprosy is an expression of multibacillary leprosy, characterised by the occurrence of nodules and/or plaques in the skin or the subcutaneous tissues.

Well-demarcated cutaneous nodule is its cardinal feature. They are present over an apparently normal skin.(8)

In our study, all patients had facial involvement. Other anatomical areas involved in our study in the descending order of frequency was found to be back, thighs, buttocks, forearms and legs, which coincides with already established studies.(9)

The pathogenesis of this unusual variant of lepromatous leprosy remains enigmatic.

Although, considered to be a variant of lepromatous leprosy, there exists an enhanced immune response against Mycobacterium leprae in these patients compared with lepromatous leprosy with respect to both cell-mediated immunity and humoral immunity. Despite the presence of adequate number of macrophages, it has been claimed that they lack the functional property to kill the bacilli that exists in high numbers in Histoid Lesion.(10)

Leprosy reactions in Histoid Hansen have been only rarely reported in the English Literature and it refers mainly to type 2 (ENL) reaction. Sehgal and Srivastava and Kalla et al described a Type 2 reaction only in one out of 23 and 2 out of 25 patients with Histoid Leprosy respectively.(11,12) Type 2 reactions can also develop after initiation of MDT (Multi-Drug Therapy) for leprosy.(13) Type I reactions are reported very rarely in Histoid Hansen,(14) usually commencing 10 weeks after Multi-Bacillary Multi-Drug Therapy.

Wade's reporting of 'Tuberculoid contamination of Histoid Lesion may be representing Type I reactions not diagnosed at that time.(15)

Patients may develop pruritic, painful, erythematous and oedematous papules, plaques and nodules over the face, trunk and extremities without constitutional symptoms.

Pruritus and ulceration of existing skin lesions could be manifestations of type 1 lepra reaction as exemplified by the occurrence of ulceration of the inframammary nodules in one of our patients.

\section{CONCLUSIONS}

This particular study is being reported to highlight the fact that monotherapy of Hansen's disease could lead on to evolution of drug-resistant Mycobacterium leprae, which could cause Histoid Hansen de novo in the susceptible contact of the primary index case.

Defaulters of monotherapy or multidrug therapy also downgrade in the spectrum towards Lepromatous leprosy as stressed by the facts and clinical findings of Nodular Infiltration of both ears, depressed nasal bridge, bilateral madarosis, high bacillary index which nicely shows Histoid Hansen evolving out of the Untreated Lepromatous Leprosy spectrum.

Thus, a defaulter poses a threat to the self and to the society by remaining as a 'point-source epidemic' of Evolution of Drug Resistant Mycobacterium Leprae. If leprosy has to be eliminated from the society, then Histoid Hansen patients pose a great threat to the goal of elimination and thus it becomes mandatory for every Health Care Worker in the field of Leprosy to conduct thorough surveillance of new case detection, reporting and ensuring of complete patient compliance as for as MB-MDT is concerned.(16)

Also transepidermal elimination of mycobacterium leprae through intact or ulcerated skin lesions of Histoid Leprosy as pointed out rightly by Ghorpade AK(17) makes Histoid Hansen a still more potential variant of leprosy as for as its disseminating potential to the susceptible contacts is concerned.

Thus, early detection and ensuring complete compliance of treatment with Multi-Bacillary Multi-Drug Therapy would help go a long way not only in the Eradication of Leprosy, but also to eradicate this rare variant of lepromatous leprosy, viz., Histoid Hansen.

\section{REFERENCES}

1. Wade HW. The histoid variety of lepromatous leprosy. Int J Lepr 1963;31:129-42.

2. Rodriguez JN. The histoid leproma: its clinical characteristics and significance. Int J Lepr 1969;37:1-21.

3. Vora RV, Pilani AP, Mehta MJ, et al. De-Novo histoid hansen cases. J Glob Infect Dis 2014;6(1):19-22.

4. Mansfield RE. Histoid leprosy. Arch Pathol 1969;87(6):580-5.

5. Manoharan R, Madhu R, Srinivasan MS. Histoid Hansen's: a case report. J Indian Soc Teledermatol 2008;2:12-6.

6. Sehgal VN, Srivastava G. Histoid leprosy. Int J Dermatol 1985;24(5):286-92.

7. Wade HW. The histoid leproma. Abstract. Int J Lepr 1960;28:469-70.

8. Ramanujam K, Ramu G. Wade's histoid lepromatous leprosy: report of a clinical study. Lepr India 1969;41:293-7.

9. Kaur I, Dogra S, De D, et al. Histoid leprosy a retrospective study of 40 cases from India. $\mathrm{Br} \mathrm{J}$ Dermatol 2009;160(2):305-10.

10. Kontochristopoulos GJ, Aroni K, Panteleos DN, et al. Immunohistochemistry in histoid leprosy. Int J Dermatol 1995;34(11):777-81.

11. Sehgal VN, Srivastava G. Status of histoid leprosy-a clinical, bacteriological, histopathological and immunological appraisal. J Dermatol 1987;14(1):38-42.

12. Kalla G, Purohit S, Vyas MC. Histoid, a clinical variant of multibacillary leprosy: report from so-called nonendemic areas. Int J Lepr Other Mycobact Dis 2000;68(3):267-71.

13. Vasavi S, Reddy BS. Histoid leprosy with erythema nodosum leprosum-a case report. Indian J Lepr 2012;84(1):27-9.

14. Singh N, Kumari R, Gupta D, et al. Type I lepra reaction in histoid leprosy. Int J Dermatol 2015;54(5):564-7.

15. Fatima MD. Maroja, cesare massone antonio pedro schettini histoid leprosy with type-1 reaction. Lepr Rev 2016;87:417-24.

16. Mendiratta V, Jain A, Chander R, et al. A nine-year clinicoepidemiological study of histoid hansen in India. J Infect Dev Ctries 2011;5(2):128-31.

17. Ghorpade AK. Transepidermal elimination of mycobacterium leprae in histoid leprosy: a case report suggesting possible participation of skin in leprosy transmission. Indian J Dermatol Venereol Leprol 2011;77(1):59-61. 